\title{
Antakya'da taşkına neden olan yan derelerde hidrograf analizi ile taşkın tahmini
}

\author{
Estimation of flood using hydrograph analysis of creeks causing of floods in Antakya
}

\author{
İsmail GEVREK ${ }^{1}$ (D) Ahmet iRVEM $^{2}$ (iD) \\ ${ }^{1}$ Burdur II Tarım ve Orman Müdürlüğü, Tefenni Ilļ̧e Müdürlüğü, Tefenni-Burdur, Türkiye. \\ ${ }^{2}$ Hatay Mustafa Kemal Üniversitesi, Ziraat Fakültesi, Biyosistem Mühendisliği Bölümü, Antakya-Hatay, Türkiye.
}

MAKALE BILGISI / ARTICLE INFO

\section{Makale tarihçesi / Article history:}

DOI: $10.37908 / \mathrm{mkutbd} .932723$

Geliş tarihi /Received:04.05.2021

Kabul tarihi/Accepted:05.07.2021

\section{Keywords:}

Synthetic hydrograph, flood analysis, Orontes river, DSI method, Mockus method.

\footnotetext{
Corresponding author: Ahmet IRVEM

$\bowtie:$ airvem@mku.edu.tr
}

Ö ZET / A B STR ACT

Aims: The aims of this study were to estimate flood flow and generate flood hydrographs having different return periods for the nine creeks in Antakya using three synthetic hydrograph methods.

Methods and Results: In this study, the maximum discharge for 2, 5, 10, 25,50 and 100 years return period is determined by using DSI, Mockus and Gray synthetic hydrograph methods. These methods were applied to Ballı̈z, Kisecik, Altinçay, Gulderen Kuyucak, Karaksi, Dikmece Arpalı and Karaali creeks. Basin features of the creeks were determined accurately and quickly using GIS. These features were used in the calculation of the synthetic methods of hydrograph components. Precipitations for different return periods have estimated using statistical methods, and run-off from precipitation was estimated using the SCS method.

Conclusions: It was found that Gray method has the maximum flood flow values. According to this method flood with 100 -year return period was estimated for Ballıöz creek is $309 \mathrm{~m}^{3} \mathrm{~s}^{-1}$, for Kisecik is $283 \mathrm{~m}^{3} \mathrm{~s}^{-1}$, for Altincay creek is $169 \mathrm{~m}^{3} \mathrm{~s}^{-1}$, for Karaksi creek is $295 \mathrm{~m}^{3} \mathrm{~s}^{-1}$, for Gülderen creek is $131 \mathrm{~m}^{3} \mathrm{~s}^{-1}$, for Kuyucak creek is $92 \mathrm{~m}^{3} \mathrm{~s}^{-1}$, for Dikmece creek is 270 $\mathrm{m}^{3} \mathrm{~s}^{-1}$, for Arpalı creek is $141 \mathrm{~m}^{3} \mathrm{~s}^{-1}$ and for Karaali creek is $196 \mathrm{~m}^{3} \mathrm{~s}^{-1}$. These flood values were recommended to use for design of flood protection structures.

Significance and Impact of the Study: Floods are one of the natural disasters causing loss of life and property. Various flood prevention and flood protection structures are projected to decrease effect of flood disaster. The most important criteria for a flood protection project is the knowledge of maximum flood discharge. However, there are no stream discharge observations for creeks flow through Orontes River in Antakya. In this study, the maximum discharge for 2, 5, 10, 25, 50 and 100 years return period is determined for 9 creeks by using synthetic hydrograph methods. The results of this study made a significant contribution to the decision-makers to plan and project the flood prevention water structures more accurately.

Atıf / Citation: Gevrek i, İrvem A (2021) Antakya'da taşkına neden olan yan derelerde hidrograf analizi ile taşkın tahmini. MKU. Tar. Bil. Derg. 26(3) : 533-542. DOI: 10.37908/mkutbd.932723

\section{GiRiş}

Taşkınlar, bir doğa olayı olarak akarsu havzalarında çeşitli nedenlerle su seviyesinin hızla yükselmesi sonucunda debinin akarsu yatak kapasitesini aşarak, suların akarsu yatağı dışına taşması olarak adlandırılır. Türkiye'de büyük taşkınlar bölgesel iklim, topografya ve yağış alanı büyüklüğü gibi etkenlerin bir araya 
gelmesiyle oluşmaktadır. Taşkınlar sadece tarım arazilerinde olmamakta, şehirlerde bulunan dere yataklarının taşmasıyla da çok sayıda can kaybına ve önemli miktarlarda ekonomik zararlara neden olmaktadır.

Taşkınlar, mal ve can kaybına neden olmakta, toprakta biyolojik ve fiziksel zararlara yol açmakta ve ekolojik dengeyi olumsuz etkilemektedir. Bu olumsuz etkileri önlemek ya da taşkın riskinin zararlarını azaltmak konusunda yapılacak çalışmaların önemi giderek artmaktadır. Türkiye'de topografik yapıdan dolayı taşkına neden olabilecek çok sayıda akarsu vardır. Bu akarsuların hepsi için akım ölçümleri yapılamamaktadır. Ancak büyük akarsular için Devlet Su Iş̧leri (DSi) ve Elektrik İşleri Etüt İdaresi (EiEi) akım ölçümleri yapabilmekteydi. Akım ölçümü olmayan küçük akarsularda taşkın debileri bilinmediği için bu akarsular üzerinde yapılacak kanal, köprü gibi sanat yapılarının projelenmesinde sorunlar yaşanmaktadır. Kimi ölçümü olmayan akarsuların taşkın debilerinin tahmini için ampirik olarak geliştirilen ve akarsuyun havza parametrelerinin kullanıldığı sentetik hidrograf yöntemleri geliştirilmiştir.

Bir akarsuyun debisinin zamana göre grafiğine hidrograf denir. Bir havzada bir birim yüzey akışın oluşturduğu hidrografa birim hidrograf denir. Birim hidrograflar, yağış ve yüzey akış verileri bulunmayan havzalarda, havzanın fiziksel özellikleri kullanılarak oluşturulan ampirik eşitlikler yardımıyla sentetik olarak elde edilirler. Birim hidrograflardan yağış verileri kullanılarak İstenilen yinelenme yılları ve kritik süreler için taşkın debileri hesaplanabilmektedir. Türkiye'de DSi, Mockus ve Gray yöntemi yaygın olarak kullanılan hidrogaf yöntemleridir (Tülücü, 2002).

Türkiye'nin farklı bölgelerinde akım ölçümü olmayan akarsular için, sentetik yöntemler kullanılarak taşkın debilerini tahmin eden çalışmalar yapılmıştır (Sevinç, 1987; Sorman, 1995; Törün, 1998; Karaş, 2000; Demiryürek ve ark., 1999; Bakanoğulları ve Baran, 2002; Oğuz ve Balçın, 2002; Oğuz ve Balçın, 2003).

Bakanoğulları ve Günay (2011) Vize deresinde $4.64 \mathrm{~km}^{2}$ alana sahip havzada yapmış oldukları çalışmalarında, havzaya 3 adet yağış istasyonu kurulmuş ve havza çıkışında $1 / 5$ şevli beton savak ile bir limnigraf yerleştirmişlerdir. Araştırmanın 1985-2007 su yıllarını kapsayan döneminde 23 yıllık yağış ve yıllık akım değerleri ölçülmüştür. Havzanın 23 yıllık yağış ortalaması $544.2 \mathrm{~mm}$, akım ortalaması $6.04 \mathrm{~mm}$ olarak belirlenmiştir. Araştırma sonucunda, havza yıllık ortalama yüzey akış katsayısını \% 0.53 , havzanın 60 dakika süreli ortalama birim hidrografında pik debisini (qp) $354.63 \mathrm{~L} \mathrm{~s}^{-1}$, taban süresi (tb) 14.43 saat, pike erişme süresi (tp) 1.63 saat olarak belirlemişlerdir. Benzer havzaların birim hidrograflarının sentetik olarak çıkarılmasında kullanılan Snyder metodu katsayıları olan $C_{t}=0.311$ ve $C_{p}=0.293$ olarak, Mockus metodu katsayıları $\mathrm{K}=0,119$ ve $\mathrm{H}=3.95$ olarak hesaplamışlardır. Öztürk ve Apaydın (1997), Türkiye'de seçilen birkaç küçük su toplama havzasında belirli yinelenme aralığına sahip, farklı yöntemlerle hesaplanan pik debilerle, akış gözlemlerinden elde edilen debileri karşılaştırmışlardır. Alanları 1.20 ile $26.25 \mathrm{~km}^{2}$ arasında değişen havzalarda, birim hidrograf yöntemi, rasyonel yöntem, Mc.Math yöntemi, SCS grafik yöntemi, Snyder ve Mockus yöntemlerini kullanmışlar ve uygun yöntemin seçiminin, veri varlığına, proje ihtiyacına, havza büyüklüğüne, uygulama ve yöntem kısıtlarına bağlı olacağını belirtmişlerdir. Yabancı ülkelerde de sıkça bu yöntemlere başvurularak taşkın debisi tahminleri yapılmıştır (Ashfaq ve Webster, 2000; Chandrmohan ve Durbude, 2001; Hromadka ve Whitley, 1994; Sheridan, 1994).

Bu çalışmanın amacı, Antakya il merkezinden geçen ve Asi nehrine dökülen yan derelerin CBS ile havza alanlarının ve özelliklerinin belirlenmesi, bu özellikleri kullanarak, derelerin farklı yinelenme yılları için taşkın debilerini, DSi, Mockus ve Gray sentetik hidrograf yöntemleri ile belirlemektir.

\section{MATERYAL ve YÖNTEM}

\section{Çalışma alanı}

Çalışma, Antakya il merkezinden geçen Ballıöz, Kisecik, Altınçay, Karaksı, Dikmece, Güldüren, Kuyucak, Arpalı ve Karaali isimli yan derelerde yürütülmüştür. Ballıöz ve Kisecik dereleri Antakya yerleşim merkezine doğru birleşerek her iki kol Hanna deresi adını almaktadır. Şekil 1'de çalışma alanı ve derelerin konumu verilmiştir. Hücre tabanlı (27×27 metre) topoğrafik harita NASA, GLD veri tabanından raster olarak elde edilmiştir. Çalışma alanı bitki örtüsü ve arazi kullanım haritaları 1:25 000 ve 1:100 000 ölçekli il Özel İdaresine ait haritalardan yararlanılmıştır. Derelerin konumu, toprak özellikleri, yağış verileri, bitki örtüsü, arazi kullanım durumunun sayısallaştırılarak veri tabanın oluşturulmasında, ArcGIS ve ILWIS 3.6 Coğrafi Bilgi Sistemleri (CBS) paket programları kullanılmıştır. Antakya meteoroloji istasyonuna ait 1960-2014 yılları arası 24 saatlik maksimum yağış verileri Devlet Meteoroloji İşleri Genel Müdürlüğünden (DMi) temin edilmiştir. 


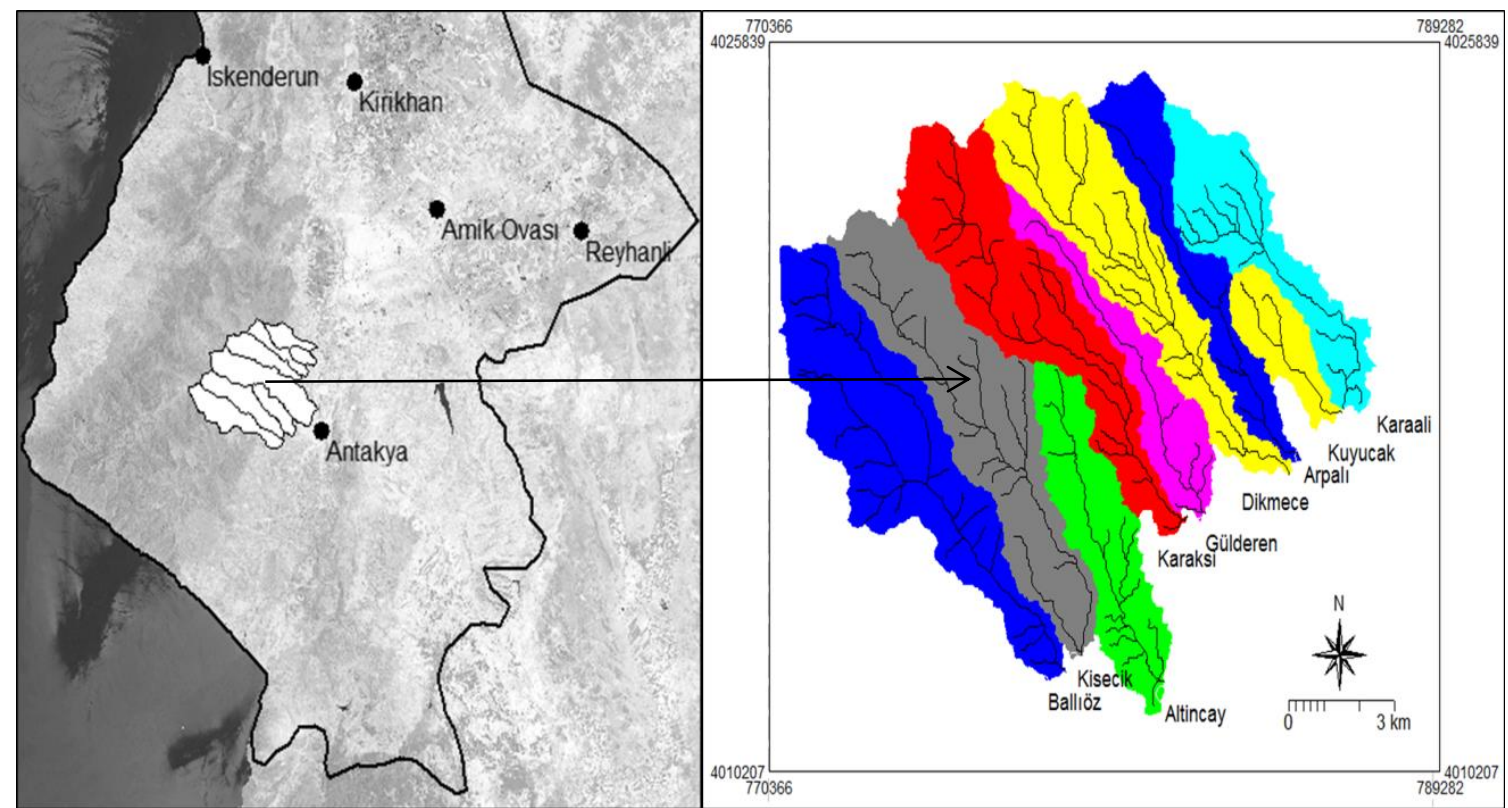

Şekil 1. Çalışma alanı ve derelerin konumu

Figure 1. Study area and location of creeks

\section{Mockus yöntemi}

Mockus yöntemi ile bir sentetik birim hidrografın geliştirilmesinde, havzaya ait ana akarsu yolu uzunluğu ve eğimi kullanılarak, taşkın toplanma zamanının hesaplanması ile başlanmaktadır. Toplanma zamanı (Tc) 30 saate kadar olan havzalar için uygulanmaktadır. Tc aşağıda verilen eşitlik ile hesaplanmaktadır (Mockus, 1949).

$T c=0.00032\left(\frac{L^{0.77}}{S^{0.85}}\right)$

Burada; Tc, toplanma zamanı (saat), L, ana suyolu uzunluğu $(m)$, $S$ ise harmonik eğimdir.

Havzadan meydana gelen birim taşkın pik debisi aşağıdaki eşitlikle hesaplanır.

$q p=\frac{0.208 A}{T p}$

Burada; $q p$, birim taşkın pik debisi $\left(\mathrm{m}^{3} \mathrm{~s}^{-1}\right), A$, havza alanı $\left(\mathrm{km}^{2}\right)$ ve $T p$ ise pike erişme süresidir (saat)

\section{DSi yöntemi}

Bu yöntem, 1000 km²ye kadar olan drenaj alanları için kullanılmaktadır. Daha büyük alanlar, küçük alanlara ayrılarak her biri için ayrı hidrograf çizilir ve drenaj alanında ayrılmış olan kesitlerine göre geciktirilen hidrograflar noktalanarak bütün drenaj alanına ait hidrograf elde edilir. Bu yöntemde $1 \mathrm{~mm}^{\prime}$ lik akış yüksekliğinin toplam alandan oluşturacağı debi $\left(\mathrm{m}^{3} \mathrm{~s}^{-1}\right)$;
$Q_{p}=q p \cdot A$

Burada $A$, havza alanı $\left(\mathrm{km}^{2}\right)$ ve $q p$ ise $1 \mathrm{~mm}^{\prime}$ lik akış yüksekliğinin birim alanda oluşturacağı debidir ve aşağıda verilen formül ile hesaplanır;

$q p=\frac{414}{A^{0.225} E^{0.16}}$

Burada, $q p$ birim debiyi $\left(\mathrm{m}^{3} \mathrm{sn}^{-1} \mathrm{~mm}^{-1}\right), A$, Havza alanı $\left(\mathrm{km}^{2}\right)$ ve $\mathrm{E}$ bir parametre olup aşağıdaki şekilde hesaplanır.

$E=\frac{L L_{c}}{\sqrt{s}}$

Burada, $L$, ana suyolu uzunluğu $(\mathrm{km}), L_{c}$, havza ağırlık merkezinin ana suyolu üzerindeki izdüşümü ile havza çıkış noktası arasındaki suyolu mesafesi, $(\mathrm{km})$ ve $\mathrm{S}$, havza harmonik eğimidir (\%).

$1 \mathrm{~mm}$ 'lik akış yüksekliğinin toplam alandan oluşturacağı su hacmi $\left(\mathrm{m}^{3}\right)$;

$V b=A \cdot h$

Burada, $h$, akış yüksekliği $(\mathrm{mm}), A$, havza alanıdır $\left(\mathrm{km}^{2}\right)$

Hidrografın taban süresi;

$T b=3.65 \frac{V b}{Q_{P}}$ 
Burada; $V b, 1 \mathrm{~mm}$ 'lik akış yüksekliğinin toplam alandan oluşturacağı su hacmidir $\left(\mathrm{m}^{3}\right)$.

Hidrografın pike erişme süresi;

$$
T p=\frac{T b}{5}
$$

Burada; $T b$, hidrograf taban süresidir (saat) (Tülücü, 2002).

\section{Gray yöntemi}

Gamma dağılımına bağlı olarak Gray tarafından geliştirilen sentetik birim hidrograf yöntemidir. Taşkın debisi tahmini aşağıda verilen denklem ile yapılır (Viessman and Lewis, 1995).

$Q_{\frac{t}{P R}}=\frac{25.0\left(\frac{t}{P R} \gamma\right)^{q}}{\tau(q)}\left(e^{-\gamma\left(\frac{t}{P R}\right)}\right)\left(\frac{t}{P_{R}}\right)^{q-1}$

Burada,

$Q_{t / P R}=$ verilen $\mathrm{t} / \mathrm{P}_{\mathrm{R}}$ değeri için yüzde akış miktarı, q ve $\mathrm{\gamma}$ : şekil parametrelerini, $\tau(\mathrm{q})$ : q için gamma fonksiyonunu, $P_{R}$, yükselme parametresini ve $t$, zamanı (dakika) göstermektedir.

\section{BULGULAR ve TARTIŞMA}

\section{Maksimum yağışların analizi}

Bu çalışmada, Antakya yağış gözlem istasyonunda elde edilen 24 saatlik maksimum yağış verileri kullanılmıştır. Kolmogrow-Smirnov testi sonucuna göre, yağış değerlerinin \% 5 önem düzeyinde Gumbel dağılımına uyduğu görülmüştür. Gumbel dağılım parametreleri kullanılarak farklı yinelenme yılları için 24 saatlik maksimum yağış değerleri hesaplanmıştır. Yapılan istatistiksel hesaplamalara göre 24 saatlik maksimum yağışların 54 yıllık yağış ortalaması $98 \mathrm{~mm}$, standart sapması $60.8 \mathrm{~mm}$ bulunmuştur. Ayrıca, 2 yıl yinelenmeli 24 saatlik maksimum yağış $88 \mathrm{~mm}, 5$ yıl yinelemeli maksimum yağıs $142 \mathrm{~mm}, 10$ yıl yinelemeli maksimum yağış $177 \mathrm{~mm}, 25$ yıl yinelemeli maksimum yağış 223 mm, 50 yıl yinelemeli maksimum yağış $255 \mathrm{~mm}$ ve 100 yıl yinelemeli maksimum yağış ise $288 \mathrm{~mm}$ olarak hesaplanmıştır. Bu yağış değerleri farklı yinelenme yılları için artım akışların belirlenmesinde kullanılmıştır.

\section{Derelerin havza sınırları ve özellikleri}

Derelerin havza sınırları, öncelikle çalışma alanı sayısal topografik haritasının ILWIS CBS paket programına aktarılması ile raster (hücre tabanlı) hale getirilmiştir. Bu harita kullanılarak su akış yönleri, su birikim haritası ve akarsu kollarını veren akarsu derecelendirme haritaları elde edilmiştir (Şekil 2).

Akarsu havzalarına ait özellikler CBS yardımı ile elde edilmiş ve Çizelge 1 'de verilmiştir.

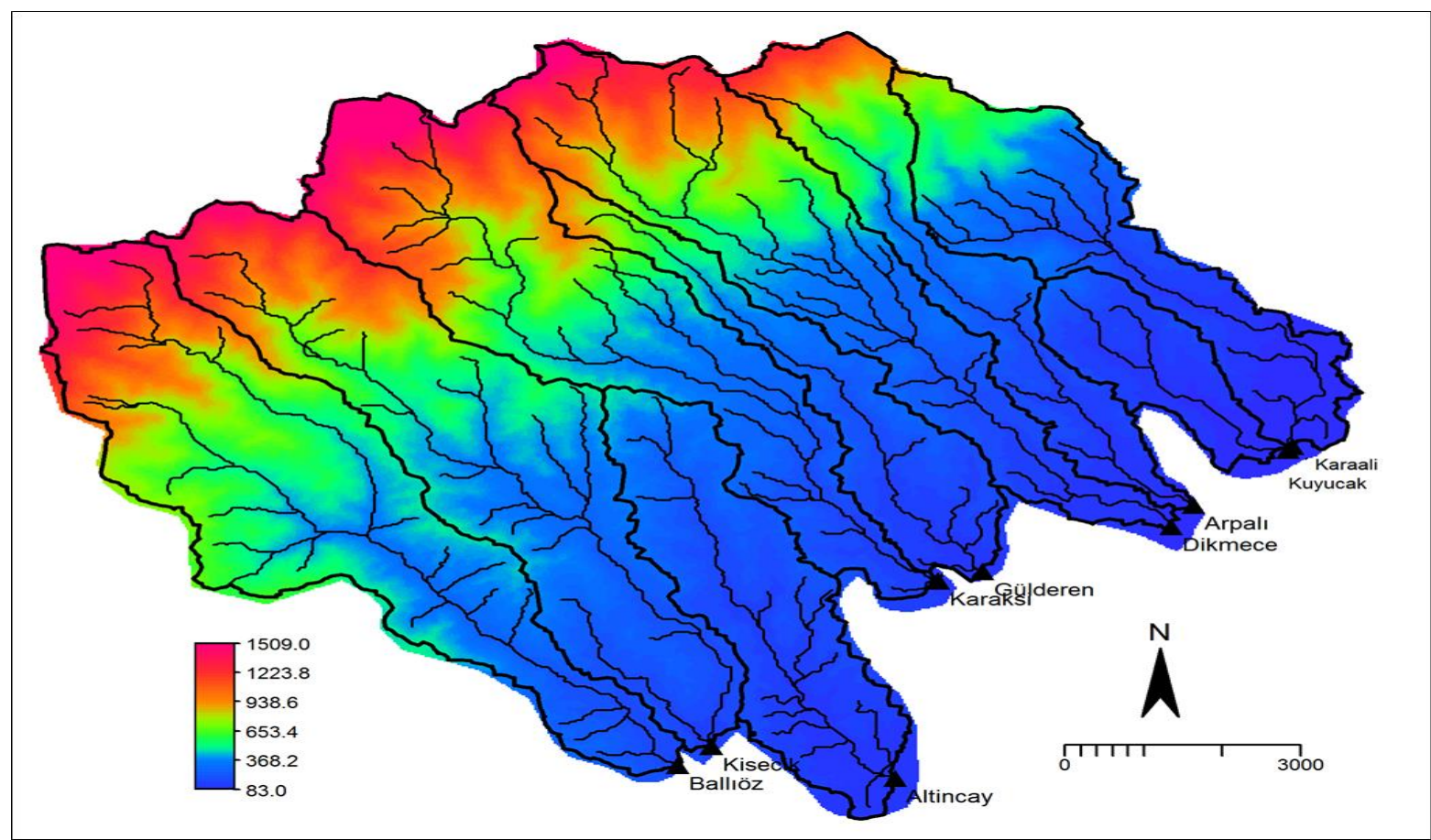

Şekil 2. Derelerin havza sınırlarını ve su akış yollarını gösteren sayısal yükseklik haritası

Figure 2. Digital Elevation Map showing basins borders and streams of creeks 
Çizelge 1. Derelerin havza özellikleri

Table 1. Basin characteristics of creeks

\begin{tabular}{ccccccccccc}
\hline Dere adı & Alan $\left(\mathbf{k m}^{2}\right)$ & $\begin{array}{c}\text { Çevre } \\
\text { Uzunluğu } \\
(\mathbf{k m})\end{array}$ & $\begin{array}{c}\mathbf{L} \\
\mathbf{( k m})\end{array}$ & $\mathbf{L c}(\mathbf{k m})$ & $\mathbf{C N}$ & $\mathbf{S}$ & $\mathbf{T c}$ & $\begin{array}{c}\text { Min. } \\
\text { Yük. } \\
(\mathbf{m})\end{array}$ & $\begin{array}{c}\text { Max. } \\
\text { Yük. } \\
(\mathbf{m})\end{array}$ & $\begin{array}{c}\text { Harmonik } \\
\text { eğim }\end{array}$ \\
\hline Ballıöz & 23.14 & 31.2 & 13 & 7.8 & 76 & 0.061 & 1.40 & 150 & 1640 & 0.061 \\
Kisecik & 21.59 & 28.5 & 12.3 & 6.9 & 76 & 0.050 & 1.45 & 142 & 1400 & 0.050 \\
Altınçay & 11.92 & 17.8 & 8.2 & 4.4 & 79 & 0.021 & 1.48 & 100 & 400 & 0.021 \\
Karaksı & 20.09 & 29.0 & 12.0 & 7.3 & 78 & 0.062 & 1.31 & 125 & 1600 & 0.062 \\
Gülderen & 8.28 & 20.2 & 8.0 & 2.8 & 77 & 0.051 & 1.03 & 100 & 890 & 0.051 \\
Dikmece & 18.12 & 26.0 & 12.9 & 7.0 & 79 & 0.065 & 1.36 & 84 & 1560 & 0.065 \\
Arpalı & 9.91 & 22.0 & 10.8 & 5.5 & 78 & 0.042 & 1.40 & 92 & 1290 & 0.042 \\
Kuyucak & 4.73 & 10.0 & 4.3 & 2.8 & 81 & 0.025 & 0.84 & 74 & 295 & 0.025 \\
Karaali & 11.76 & 19.0 & 7.3 & 5.0 & 77 & 0.064 & 0.88 & 78 & 910 & 0.064 \\
\hline
\end{tabular}

Derelerin harmonik eğimlerinin hesabı

Derelerin harmonik eğimleri, CBS ve SYH kullanılarak hesaplanmıştır. Tüm dereler için bulunan sonuçlar Çizelge 1 'de verilmiştir.
Örnek olması amacıyla Ballı̈z deresi için yapılan hesaplamalar Çizelge 2'de verilmiştir.

Çizelge 2. Balıöz deresi harmonik eğimi hesaplamaları

Table 2. Calculation of harmonic slope for Ballıoz creek

\begin{tabular}{|c|c|c|c|c|c|c|}
\hline Sira no & $h$ & $\Delta \mathbf{h}$ & $\mathbf{L}$ & $S=\Delta h / L$ & $S^{0.5}$ & $1 / S^{0.5}$ \\
\hline 0 & 150 & & & & & \\
\hline 1 & 186 & 36 & 1300 & 0.03 & 0.17 & 6.01 \\
\hline 2 & 226 & 40 & 1300 & 0.03 & 0.18 & 5.70 \\
\hline 3 & 281 & 55 & 1300 & 0.04 & 0.21 & 4.86 \\
\hline 4 & 373 & 92 & 1300 & 0.07 & 0.27 & 3.76 \\
\hline 5 & 433 & 60 & 1300 & 0.05 & 0.21 & 4.65 \\
\hline 6 & 539 & 106 & 1300 & 0.08 & 0.29 & 3.50 \\
\hline 7 & 705 & 166 & 1300 & 0.13 & 0.36 & 2.80 \\
\hline 8 & 1042 & 337 & 1300 & 0.26 & 0.51 & 1.96 \\
\hline 9 & 1600 & 558 & 1300 & 0.43 & 0.66 & 1.53 \\
\hline \multirow[t]{3}{*}{10} & 1640 & 40 & 1300 & 0.03 & 0.18 & 5.70 \\
\hline & & & & & $\Sigma=$ & 40.48 \\
\hline & & & & & $\mathrm{S}=$ & 0.061 \\
\hline
\end{tabular}

\section{Derelerin DSi yöntemi ile hidrograf analizi sonuçları}

DSi yöntemi kullanılarak 9 dere için farklı yinelenmeli taşkın debileri hesaplanmıştır. Burada sadece Ballıöz deresine ait hesaplamalar ve sonuçları verilmiştir. Diğer dereler için yapılan hesaplama işlemleri ve sonuçları Gevrek (2016)'da görülebilir.

\section{Ballıöz Deresi DSi yöntemi sonuçları}

DSi sentetik yöntem ile Ballı̈z deresi için yapılan hesaplamalarda $Q p$ ve $T p$ değerleri belirlenmiş daha sonra birim hidrograf koordinat değerleri ile çarpılarak sonuçları Çizelge 3 'te verilmiştir.
$\mathrm{Bu}$ sonuçlara göre birim hidrograf elemanları belirlenmiş ve elde edilen birim hidrograf Şekil $3^{\prime}$ te verilmiştir. Ballıöz deresi için pik debi $1.80 \mathrm{~m}^{3} \mathrm{sn}^{-1}$ olarak, Pike erme süresi ise 2.60 saat olarak bulunmuştur.

Farklı yinelemeli yağış verilerinin istatistiksel analiz sonucu $5,10,25,50$ ve 100 yıl yinelemeli taşkın debileri elde edilmiştir (Chow ve ark., 1988). Bu debi değerleri ve DSi yöntem ile elde edilen birim hidrograf kullanılarak Ballı̈z deresi için geliştirilen farklı yinelenme yıllarına ait taşkın hidrografları Şekil 4'te verilmiştir. 
Çizelge 3. Ballı̈z deresi birim hidrograf hesaplamaları ve sonuçları Table 3. Unit hdydrograph calculation and results for Ballioz creek

\begin{tabular}{|c|c|c|}
\hline Hesaplamalar & Sonuç & Birim \\
\hline $\mathrm{E}=\mathrm{L}^{*} \mathrm{~L}_{\mathrm{c}} / \mathrm{S}^{1 / 2}$ & 410.56 & Boyutsuz \\
\hline $\mathrm{q}_{\mathrm{p}}=414 / \mathrm{A}^{0.225 * \mathrm{E}^{0.16}}$ & 77.96 & $\left(\mathrm{l} / \mathrm{s} / \mathrm{mm} / \mathrm{km}^{2}\right)$ \\
\hline$Q_{p}=A * q_{p} * 10^{-3}$ & 1.80 & $\left(\mathrm{~m}^{3} / \mathrm{s} / \mathrm{mm}\right)$ \\
\hline $\mathrm{V}_{\mathrm{b}}=\mathrm{A} * \mathrm{~h}_{\mathrm{a}} * 10^{3}$ & 23140 & $\left(\mathrm{~m}^{3}\right)$ \\
\hline$T=\left(3,65 V_{b} / Q_{p}\right) / 3600$ & 13.01 & $(s)$ \\
\hline $\mathrm{T}_{\mathrm{p}}=\mathrm{T} / 5$ & 2.60 & (saat) \\
\hline
\end{tabular}

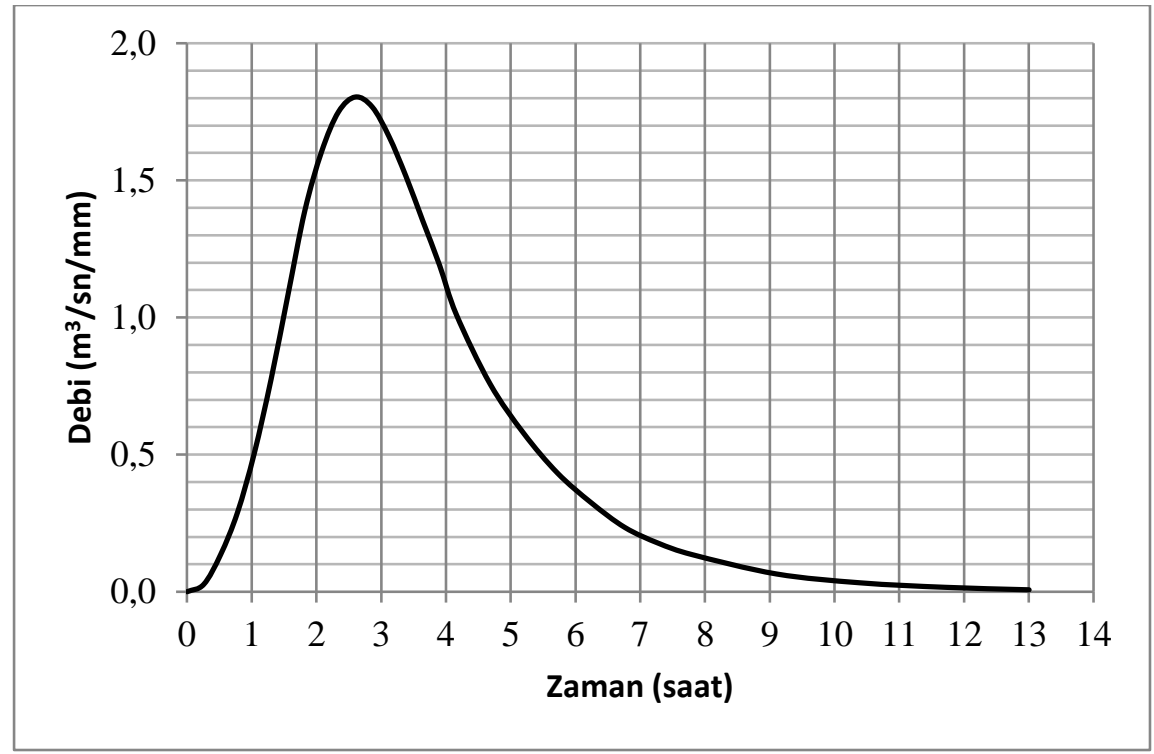

Şekil 3. Ballıöz deresi birim hidrografı

Figure 3. Unit hydrograph for Ballıoz creek

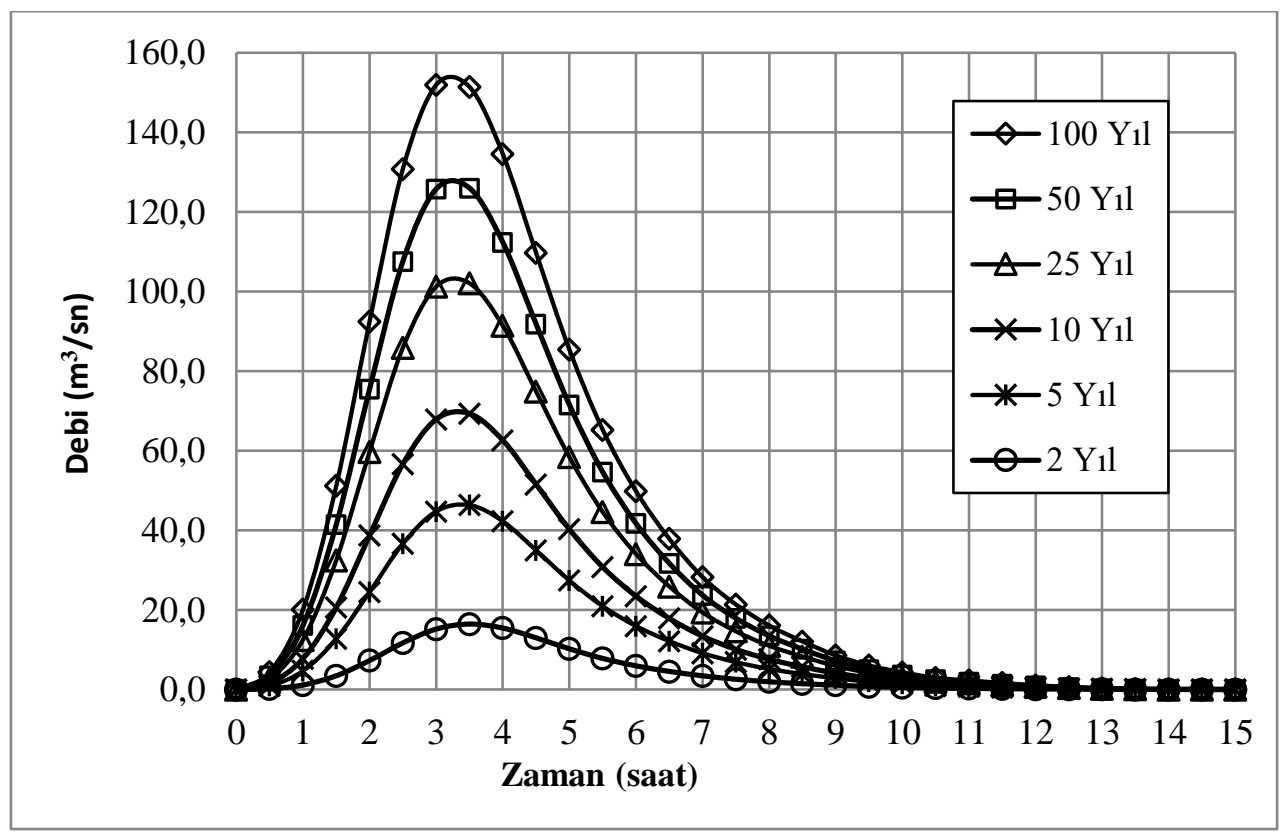

Şekil 4. DSi yöntemine göre Ballı̈z deresinin faklı yinelenme yılları için taşkın hidrografı Figure 4. Flood hydrograph of Ballioz creek for different occurence intervals according to DSI method 
Bu çalışmada yapılan Mockus ve Gray yöntemleri ile taşkın debisi hesaplamalarına ait detaylı bilgiler Gevrek (2016)'da verilmiştir. DSi yöntemi ile yapılan hesaplamalarda elde edilen taşkın debileri Çizelge 4'te, Mockus yöntemi ile elde edilen taşkın debileri Çizelge

Çizelge 4. DSi yöntemi sonuçları

Table 4. Results of DSI method

\begin{tabular}{ccccccc}
\hline Dere adı & $\mathbf{Q}_{\mathbf{2}}$ & $\mathbf{Q}_{\mathbf{5}}$ & $\mathbf{Q}_{10}$ & $\mathbf{Q}_{\mathbf{2 5}}$ & $\mathbf{Q}_{50}$ & $\mathbf{Q}_{100}$ \\
\hline Kisecik & 13.1 & 40.9 & 73.4 & 121.2 & 162.6 & 207.7 \\
Karaksı & 14.7 & 43.0 & 72.4 & 118.5 & 157.5 & 199.3 \\
Ballı̈̈z & 16.4 & 46.3 & 69.3 & 102.1 & 126.0 & 151.9 \\
Altınçay & 10.9 & 30.7 & 50.4 & 81.7 & 108.4 & 137.0 \\
Dikmece & 10.5 & 27.8 & 48.4 & 72.3 & 95.2 & 119.9 \\
Arpalı & 6.1 & 16.4 & 28.5 & 42.7 & 56.8 & 72.0 \\
\hline
\end{tabular}

Çizelge 5. Mockus yöntemi sonuçları

Table 5. Results of Mockus method

\begin{tabular}{|c|c|c|c|c|c|c|}
\hline Dere adı & $\mathbf{Q}_{2}$ & $\mathbf{Q}_{5}$ & $\mathbf{Q}_{10}$ & $\mathbf{Q}_{25}$ & $\mathbf{Q}_{50}$ & $\mathbf{Q}_{100}$ \\
\hline Ballıöz & 29.9 & 83.5 & 127.6 & 191.3 & 238.3 & 288.5 \\
\hline Karaksı & 14.3 & 51.8 & 127.3 & 186.8 & 230.4 & 276.7 \\
\hline Kisecik & 27.5 & 75.7 & 116.3 & 174.3 & 217.4 & 263.4 \\
\hline Dikmece & 29.6 & 78.4 & 116.8 & 170.3 & 209.4 & 250.9 \\
\hline Karaali & 18.4 & 50.0 & 76.9 & 116.6 & 146.3 & 178.0 \\
\hline Altınçay & 18.9 & 48.3 & 72.3 & 105.8 & 130.5 & 156.6 \\
\hline Arpalı & 14.9 & 39.7 & 59.8 & 88.1 & 108.8 & 130.9 \\
\hline Gülderen & 12.6 & 35.2 & 52.8 & 77.4 & 95.9 & 117.0 \\
\hline Kuyucak & 9.9 & 25.7 & 38.3 & 56.0 & 69.0 & 82.7 \\
\hline
\end{tabular}

Çizelge 6. Gray yöntemi sonuçları

Table 6. Results of Gray method

\begin{tabular}{ccccccc}
\hline Dere adı & $\mathbf{Q}_{\mathbf{2}}$ & $\mathbf{Q}_{\mathbf{5}}$ & $\mathbf{Q}_{\mathbf{1 0}}$ & $\mathbf{Q}_{\mathbf{2 5}}$ & $\mathbf{Q}_{\mathbf{5 0}}$ & $\mathbf{Q}_{\mathbf{1 0 0}}$ \\
\hline Ballı̈z & 30.7 & 89.7 & 136.4 & 203.0 & 254.0 & 309.0 \\
Karaksı & 32.1 & 87.7 & 132.5 & 196.8 & 244.4 & 295.0 \\
Kisecik & 28.4 & 82.3 & 126.0 & 188.0 & 233.0 & 283.0 \\
Dikmece & 31.0 & 82.5 & 122.8 & 181.2 & 224.2 & 162.0 \\
Karaali & 19.0 & 56.0 & 86.7 & 130.0 & 141.0 & 169.7 \\
Altınçay & 19.7 & 53.0 & 78.7 & 114.7 & 116.7 & 141.0 \\
Arpalı & 15.4 & 42.5 & 63.7 & 86.3 & 108.0 & 131.4 \\
Gülderen & 13.0 & 37.0 & 57.0 & 61.3 & 75.1 & 92.0 \\
Kuyucak & 11.0 & 28.7 & 42.3 & & & 7 \\
\hline
\end{tabular}


Üç yöntemin kıyaslanması açısından tüm dereler için taşkın yinelenme yıllarına göre debi değerlerini veren grafikler oluşturulmuştur (Gevrek, 2016). Burada, örnek olması amacıyla sadece Ballı̈z deresi taşkın debilerinin kıyaslanmasına ait grafik Şekil 5'te verilmiştir.

Ballı̈z deresi için Gray yöntemi ile bulunan debiler en yüksek değerleri vermiştir. Diğer yandan DSi yöntemi en az taşkın değeri verirken, Mockus ve Gray yöntemi DSi yöntemine göre yaklaşık 2 kat büyük taşkın değerleri vermiştir. Sönmez ve ark. (2012) yaptıkları çalışmalarında 4 farklı sentetik yöntemi kullanarak
İstanbul ilinde 8 adet derenin taşkın debilerini hesaplamışlar ve yöntem sonuçlarını karşılaştırdıklarında, Snyder yönteminin diğer yöntemlere göre daha büyük değerler verdiğini ifade etmişlerdir. Snyder yöntemi Kirpich yöntemine göre \% 48 - 55, Mockus yöntemine göre \% $88-170$ ve SCS (DSi) Yöntemine göre de \% 400 civarında daha büyük sonuçlar verdiğini ifade etmişlerdir. Bu çalıma da benzer şekilde DSi yöntemi en az taşkın debisi veren yöntem olmuştur.

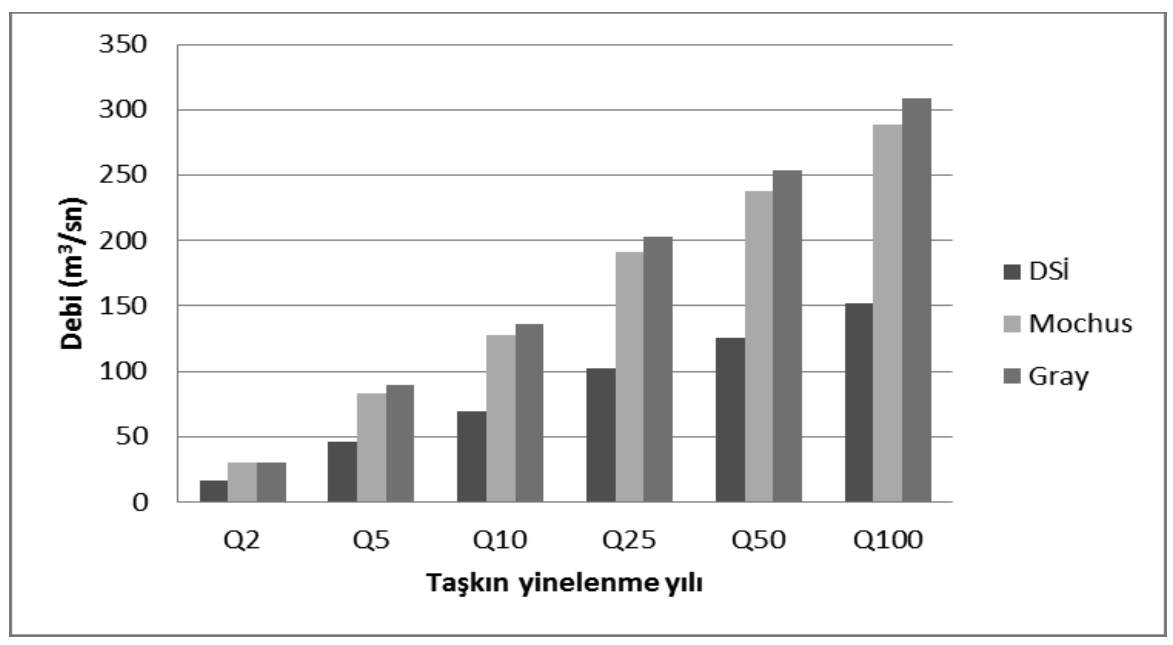

Şekil 5. Ballı̈z deresi için sentetik yöntemlerin kıyaslanması

Figure 5. Comparison of synthetic methods for Ballioz creek

Mockus ve S.C.S. Yöntemlerinin havzanın eğimi ve belirli katsayıların dikkate alındığı gibi havzaya ait katsayılar belirlenirken havza geçirimliliği, bitki örtüsü ve zemin yapısı gibi karakteristik özelliklerde dikkate alınmaktadır. Bu nedenle sonuçların diğer iki yönteme göre daha düşük çıkmasına sebep olduğunu açıklamaktadır (Sönmez ve ark., 2012).

Sonuç olarak, bu çalışmada taşkına neden olan Asi nehri yan derelerinde akım ölçümlerinin olmaması nedeniyle farklı yinelenme yılları için taşkın debileri sentetik hidrograf yöntemleri ile belirlenmiştir. Bu yöntemler DSi, Mockus ve Gray'dir. Bu yöntemlerin uygulanması için dere havzaları ve bu havzalara ait özellikler ILWIS ve ArcSWAT, CBS yazılımları ile belirlenmiştir.

Yan derelere en yakın meteoroloji istasyonu Antakya meteoroloji istasyonu olduğundan buradan alınan verilere göre 24 saatlik maksimum yağıs değerleri istatistiksel yöntemler kullanılarak 5, 10, 25, 50, 100, 500 ve 1000 yıllık yinelenme yıllarına göre hesaplanmıştır. Hesaplamalar sonucunda, 24 saatlik maksimum yağışın 2 yıl yinelenme değeri için $88 \mathrm{~mm}, 5$ yıl için 142 mm, 10 yıl için, 177 mm, 25 yıl için, 223 mm, 50 yıl için 255 mm, 100 yıl için 288 mm, 500 yıl için 364 mm ve 1000 yıl için 398 mm olarak bulunmuştur. Taşkın koruma yapıları genellikle 100 yıllık yinelenme yıllarına göre projelendiğinden, 500 ve 1000 yıllık taşkın hidrografları geliştirilmemiştir. Elde edilen havza özellikleri ile sentetik hidrograf yöntemleri için gerekli parametreler hesaplanmış ve farklı yinelenmeli yağış verileri kullanılarak değişik yinelenme yılları için taşkın debileri ve hidrografları geliştirilmiştir. Yapılan kıyaslamada sonucunda en yüksek debi değerleri Gray yönteminden elde edilmiştir. Salami ve ark. (2009) yılında Nijerya'da yaptıkları çalışmalarında Snyder, SCS ve Gray yöntemleri ile taşkın hidrografları geliştirmişlerdir ve sonuçta Gray yönteminin en büyük taşkın değerlerini verdiğini ifade etmişlerdir. Bu çalışmada da benzer şekilde Gray ve Mockus yöntemi DSi yöntemine göre daha büyük debi değerleri vermiştir. Havza alanı arttıkça debi değerlerinin arttığı görülmüştür. Gray ve Mockus yöntemi DSi yöntemine göre daha büyük debi değerleri vermiştir. Havza alanı arttıkça debi değerlerinin arttığı görülmüştür. Yöntemlerin farklı sonuçlar vermesi her yöntemin havzanın değişik karakteristik özelliklerini kullanmasından kaynaklı olduğu söylenebilir. Bu 
özelliklerin doğru ve uygun şekilde tespit edilmesi gereklidir, havza alanının büyüklüğü ve drenaj alanının eğimi kullanılacak yöntemin seçiminde en önemli faktörler olmaktadır.(Sönmez ve ark., 2012). Hangi yöntemin en iyi sonucu verdiği, ancak taşkın anında bu derelerde yapılacak debi ölçümleri ile belirlenebilecektir.

Antakya'da 1956, 1969, 1975, 1976, 1980, 1987, 1998, 2001 ve 2002 yıllarında büyük ekonomik kayıplara neden olan çeşitli büyüklükte taşkın olayları yaşanmıştır. Amik ovası kaynaklı bu taşkınlardan özellikle 21 Mayıs 1998 yılında meydana gelen taşkında yan derelerin taşkına etkisi büyük olmuştur. Belirtilen tarihte, Altınçay deresi yatak kesitinin yetersizliği önemli derecede zarara yol açan taşkına neden olmuştur. Bu taşkının debisi $88 \mathrm{~m}^{3} \mathrm{sn}^{-1}$ olarak ölçülmüştür (Anonim, 2002). Bu dere için Mockus yöntemi ile yapılan hidrograf analizinde 10 yıl yinelenmeli taşkın debisi 72 $\mathrm{m}^{3} \mathrm{sn}^{-1}, 25$ yıl içinse $105 \mathrm{~m}^{3} \mathrm{sn}^{-1}$ olarak hesaplanmıştır. Bu sonuçlara göre bu taşkın debisinin yaklaşık 20 yılda bir meydana gelebilecek bir debi olduğu görülmektedir. Bu dere için yatak kesitinin Mockus yöntemi sonuçlarına göre $156 \mathrm{~m}^{3} \mathrm{sn}^{-1}$ olarak projelenmesi önerilmektedir. Gray yönteminde ise 10 yıl yinelenmeli taşkın debisi $78.7 \mathrm{~m}^{3} \mathrm{sn}^{-1}$ olarak bulunmuştur. Bu miktar Altınçay'da meydana gelen taşkın pikine yakın bir değerdir. 10 yıl yinelenmeli taşkın debisinin bile zarara yol açması Antakya'da yan derelerin 50 ve 100 yıllık taşkın debilerine göre projelenmesinin önemini göstermektedir.

Bu çalışmada, Gray yöntemi en büyük taşkın debisi değerlerini vermiştir. Gray yöntemi sonuçlarına göre, derelerin yüzyıl yinelenmeli taşkın debileri, Ballıöz deresi için $309 \mathrm{~m}^{3} \mathrm{sn}^{-1}$, Kisecik deresi için $283 \mathrm{~m}^{3} \mathrm{sn}^{-1}$, Altınçay deresi için $169 \mathrm{~m}^{3} \mathrm{sn}^{-1}$, Karaksı deresi için 295 $\mathrm{m}^{3} \mathrm{sn}^{-1}$, Gülderen deresi için $131 \mathrm{~m}^{3} \mathrm{sn}^{-1}$, Kuyucak deresi için $92 \mathrm{~m}^{3} \mathrm{sn}^{-1}$, Dikmece deresi için $270 \mathrm{~m}^{3} \mathrm{sn}^{-1}$, Arpalı deresi için $141 \mathrm{~m}^{3} \mathrm{sn}^{-1}$ ve Karaali deresi için $196 \mathrm{~m}^{3} \mathrm{sn}^{-1}$ olarak tahmin edilmiştir. Bu taşkın debilerinin derelerin ıslahında ve taşkın koruma yapılarının projelenmesinde, taşkın debisi olarak kullanılması önerilmektedir. Ancak bunun yanında iyi bir risk ve ekonomik analizlerinin de yapılması gereklidir. Ayrıca yerel yönetimlerin taşkın senaryoları hazırlayarak drenaj sistemine önem vermeleri ve muhtemel taşkınlara karşı acil eylem planı hazırlamaları gereklidir. Bir havzayla ilgili taşkın debisi miktarları tahmin etmede kullanılacak yöntemin uygulanmasında yağış miktarları, akış ölçümleri, havzanın karakteristik özellikleri doğru şekilde tespit edilmelidir. Havza alanının büyüklüğü ve drenaj alanının eğimi kullanılacak yöntemin seçiminde belirleyici rol oynamaktadır. Ayrıca, bundan sonraki çalışmalarda daha doğru ve kesin sonuçların elde edilmesinde derelerde düzenli ve sürekli debi ölçümlerinin ilgili kurum ve kuruluşlar tarafından yapılması büyük önem arz etmektedir.

\section{ÖZET}

Amaç: Bu çalışmanın amacı, Antakya merkezinden geçen ve debi ölçümü olmayan, yan derelerde meydana gelebilecek 2, 5, 10, 25, 50 ve 100 yıllık yinelenmeli taşkın debilerinin sentetik hidrograf yöntemleri ile tahmin edilmesidir.

Yöntem ve Bulgular: Bu çalışmada, Ballıöz, Kisecik, Altınçay, Gülderen, Kuyucak, Karaksı, Dikmece, Arpalı ve Karaali derelerinin havza parametreleri CBS ile belirlenmiş ve DSi, Mockus ve Gray sentetik yöntemlerinin hidrograf elemanlarını hesaplamada kullanılmıştır. İstatistiksel yöntemlerle farklı yinelenmeli yağış verileri elde edilmiş, Bu veriler SCS yönteminde kullanılarak, yağış verilerinden yüzey akış tahmin edilerek, üç sentetik yönteme göre derelerin 5, 25, 50, 100 yıllık taşkın hidrografları oluşturulmuştur. Yöntemlerin kıyaslanması sonucunda Gray yöntemi en büyük taşkın debisi değerlerini vermiştir. Gray yöntemi ile 100 yıllık taşkın debisi, Ballıöz deresi için $309 \mathrm{~m}^{3} \mathrm{sn}^{-1}$, Kisecik için $283 \mathrm{~m}^{3} \mathrm{sn}^{-1}$, Altınçay için $169 \mathrm{~m}^{3} \mathrm{sn}^{-1}$, Karaksı için $295 \mathrm{~m}^{3} \mathrm{sn}^{-1}$, Gülderen için $131 \mathrm{~m}^{3} \mathrm{sn}^{-1}$, Kuyucak için $92 \mathrm{~m}^{3} \mathrm{sn}^{-1}$, Dikmece için $270 \mathrm{~m}^{3} \mathrm{sn}^{-1}$, Arpalı için $141 \mathrm{~m}^{3}$ $\mathrm{sn}^{-1}$, Karaali için $196 \mathrm{~m}^{3} \mathrm{sn}^{-1}$ olarak tahmin edilmiştir. Taşkın debilerinin Mockus yönteminde, Gray'e göre yaklaşık \%7 daha az, DSi yönteminde ise Gray'e göre yaklaşık \%50 daha az olduğu gözlenmiştir.

Genel Yorum: Bu çalışma ile Antakya'da, taşkına neden olan ve akım ölçümü olmayan yan derelerin, havza parametrelerinden farklı yinelenme yılları için 3 farklı yöntem ile taşkın debileri hesaplanmıştır. Bu derelerde yapılacak taşkın önleme yapılarının planlanmasında proje debisi olarak en büyük taşkın debisini veren Gray yönteminden elde edilen debi değerlerinin kullanılması önerilmiştir.

Çalışmanın Önemi ve Etkisi: Taşkınlar mal ve can kaybına neden olan doğal afetlerden biridir. Taşkınların zararından korunmak için çeşitli taşkın önleme ve koruma yapıları projelenir. $\mathrm{Bu}$ yapıların projelenmesinde bilinmesi gereken en önemli kriter taşkın debisidir. Taşkın debi değerleri, akım ölçümü olmayan akarsularda sentetik yöntemler kullanılarak hesaplanmaktadır. Bu çalışma ile Antakya merkezde bulunan 9 dere için farklı yinelenme yılları için taşkın debileri hesaplanmıştır. Karar vericilerin, taşkını önleyici su yapılarının daha doğru bir şekilde planlanmaları ve projelenmeleri konusunda, bu çalışmanın sonuçları 
önemli katkı sağlamıştır.

Anahtar Kelimeler: Sentetik hidrograf, taşkın analizi, Asi nehri, DSi yöntemi, Mockus yöntemi.

\section{TEŞEKKÜR}

Bu çalışma, Hatay Mustafa Kemal Üniversitesi, Fen Bilimleri Enstitüsü, Biyosistem Mühendisliği Anabilim Dalında İsmail GEVREK tarafından yapılmış olan, 895 nolu yüksek lisans tez çalışmasından hazırlanmıştır.

\section{ÇIKAR ÇATIŞMA BEYANI}

Makale yazarları aralarında herhangi bir çıkar çatışması olmadığını beyan ederler.

\section{ARAŞTIRMACILARIN KATKI ORANI BEYANI}

Yazarlar makaleye eşit oranda katkı sağlamış olduklarını beyan ederler.

\section{KAYNAKLAR}

Anonim (2002) Hatay-Antakya Asi nehri yan dereleri yukarı havza ıslahı ön inceleme raporu. DSi Genel Müdürlüğü yayınları, Yayın No: 290121, Ankara.

Ashfaq A, Webster P (2000) The timing of runoff response in desing flood analysis. Hydrol. Process. 14(7): 1217-1233.

Bakanoğulları F, Günay S (2011) Kırklareli Vize Deresi Havzası birim hidrograf elemanlarının belirlenmesi. Tar. Bil. Ar. Der. 4(2): 7-13.

Chandrmohan T, Durbude DG (2001) Estimation of runoff using small watershed models. J. Hydrol. 24(2): 45-53.

Chow VT, Maidment D, Mays LV (1988) Applied hydrology. McGraw-Hill Book Company, New York. pp 572.

Demiryürek M, Tongarlak E, Okur M (1999). KonyaÇiftliközü Karabalçık Deresi Havzası yağı̧̧ ve akış karakteristikleri. KHGM Toprak ve Su Kaynakları Araştırma Sonuç Raporu, APK Dairesi Başkanlığı, Ankara. $115 \mathrm{~s}$.

Gevrek i (2016) Antakya'da taşkina neden olan yan derelerde hidrograf analizi ile taşkin tahmini. Yüksek Lisans Tezi, Hatay Mustafa Kemal Üni., Fen Bil. Ens., Biyosistem Mühendisliği ABD, $119 \mathrm{~s}$.

Hromadka TV, Whitley RJ (1994). The rational method for peak flow-rate estimation. Water Resour. Bull. 30(6): 1001-1009.

Karaş E (2000) Bilecik-Pazaryeri Kurukavak Deresi Havzası yağış ve akış karakteristikleri. KHGM Toprak ve Su Kaynakları Araştırma Sonuç Raporu, APK Dairesi Başkanlığı, Ankara. 117s.
Mockus V (1949) Estimation of total (and peak rates of) surface run-off for individual storms. Exhibits $A$, Appendix B, Interim Survey Report, Grand (Neosho) River Watershed. U.S. Department of Agriculture, Washington DC. pp 61.

Oğuz i, Balçın M (2003) Tokat-Uğrak Deresi Havzası yağış ve akış karakteristikleri. KHGM Toprak ve Su Kaynakları Araştırma Sonuç Raporu, APK Dairesi Başkanlığı, Ankara. $124 \mathrm{~s}$.

Öztürk F, Apaydın H (1997) Açık drenaj kanalı proje debisinin belirlenmesinde kullanılan yöntemlerin karşılaştırılması. Uludağ Üniversitesi, Ziraat Fakültesi ve Kültürteknik Derneği, 6 . Ulusal Kültürteknik Kongresi, 5-8 Haziran, Bursa, Türkiye. 104-112 s.

Salami AW, Bilewu SO, Ayanshola AM ve Oritola SF (2009) Evaluation of synthetic unit hydrograph methods for the development of design storm hydrographs for Rivers in South-West, Nigeria, J. American Sci. 5(4): 23-32.

Sevinç AN (1987) Eskişehir-Karapazar-Çayır Havzası yağış ve akış karakteristikleri. Köy Hizmetleri Araştırma Enstitüsü yayınları, Yayın No: 204, Eskişehir.

Sheridan JM (1994) Hydrograph time parameters for flatland watersheds. Transactions of the ASAE 37: 103-113.

Sorman AU (1995) Estimation of peak discharge using GIUH model in Saudi-Arabia. J. Water Res. PL-ASCE 121(4): 287-293.

Sönmez O, Öztürk M, Doğan E (2012) İstanbul derelerinin taşkın debilerinin tahmini SAÜ. Fen Bil. Derg. 16(2): 130-135.

Törün MA (1998) Samsun Ayvalı Deresi Havzası yağış ve akış karakteristikleri. KHGM Toprak ve Su Kaynakları Araştırma Sonuç Raporu, APK Dairesi Başkanlığı, Ankara. $106 \mathrm{~s}$.

Tülücü K (2002) Hidroloji. Çukurova Üniversitesi, Ziraat Fakültesi, Yayın No: 139, Ders Kitapları Yayın No: A44, Adana.

Viesman WJ, Lewis GL (1995) Introduction to hydrology. Happer Collins College Publishers, USA. pp 780. 